\title{
Features of the clinical and morphological picture of pulmonary sarcoidosis
} \author{
Gulnazira Imanbayeva ${ }^{1}$ \\ ${ }^{1}$ Karaganda State Medical University, Karaganda, \\ Kazakhstan \\ ${ }^{2}$ Medical Centre hospital of president's affairs \\ administration, Astana, Kazakhstan
}

Maida Tussupbekova $^{1}$, Rosa Bakenova ${ }^{2}$, Leila Stabayeva ${ }^{1}$, Rayhan Nygizbaeva ${ }^{1}$,

This work is licensed under a

Creative Commons Attribution 4.0 International License

Received: 29.11.17

Accepted: 22.12 .17

UDC: 616.1

\section{J Clin Med Kaz 2017; 4(46):33-36}

Correspondence Author: Стабаева Лейла Медеубаевна -г.Караганда, ул.Тулепова 3-78, Тел: +7 701 3277033, e-mail: stabaewa@mail.ru
Abstract

The article presents an interesting clinical observation, in which, with sufficient illustration of the stages of the course and diagnosis of sarcoidosis of the lungs and peripheral lymph nodes, the diagnosis was difficult to diagnose. Late diagnosis and lack of correct therapy makes a prediction in patients with lung sarcoidosis unfavorable. These morphological criteria for the diagnosis of sarcoidosis of the lungs and lymph nodes are necessary for use in the practice of a pathomorphologic physician in order to verify the clinical diagnosis, which will allow us to determine the adequate tactics for examining, administering, correcting therapy and assessing the disease prognosis, taking into account the clinical and laboratory data revealed, the results of instrumental methods research.

Key words: granulomatous lung diseases - sarcoidosis - granuloma.

ӨКПЕ САРКОИДОЗЫНЫҢ КЛИНИКА- МОРФОЛОГИЯЛЫҚ ДИАГНОСТИКА КӨРІНІСІНІН ЕРЕКШЕЛІГІ

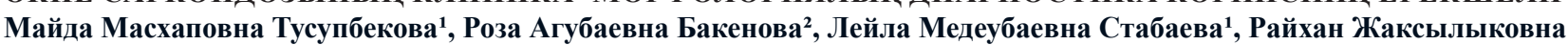

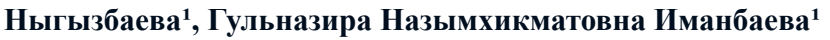

${ }^{1}$ Қарағанды Мемлекеттік Медицина Университеті

${ }^{2}$ Қазақстан Республикасы Президенті Іс Баскармасы Медициналык орталығы Ауруханасы

\section{тұЖЫРЫМДАМА}

Осы мақалада қызықты клиникалық мысал келтірілген, өкпе және шеткері лимфа түйіндерінің саркоидозының ағымын және диагностика кезеңдеріне жеткілікті иллюстрациялар болса да, диагноз құру қиындық тудырған.Өкпе саркоидозымен науқастарда кеш диагностикалаужәнедұрыс ем шараларының болмауы аурудың болжамын қатерлендіреді. Өкпе және шеткері лимфа түйіндерінің саркоидозын диагностикалаудың морфологиялық критерии мәліметтері клиникалық диагнозды нақтылау мақсатында дәрігер-патоморфологтың тәжірибесінде қолдану үшін қажет. Зерттеудің дұрыс жолын, емдеудің коррекциясымен ауру болжамын бағалаумен, клиника-лабораторлық және құрал - жабдықтық зерттеу нәтижелерінің мәліметтерді анықтауға мүмкіндік береді.

Маңызды сөздер: гранулематозды өкпе аурулары - саркоидоз - гранулема.

\section{ОСОБЕННОСТИ КЛИНИКО-МОРФОЛОГИЧЕСКОЙ ДИАГНОСТИКИ САРКОИДОЗА ЛЕГКИХ}

Майда Масхаповна Тусупбекова ${ }^{1}$, Роза АгубаевнаБакенова ${ }^{2}$, Лейла Медеубаевна Стабаева ${ }^{1}$, Райхан Жаксылыковна

Ныгызбаева ${ }^{1}$, Гульназира Назымхикматовна Иманбаева ${ }^{1}$

${ }^{1}$ Карагандинский государственный медицинский университет

Больница Медицинского Центра Управления делами ПрезидентаРеспублики Казахстан

\section{PEЗЮME}

В статье приведено интересное клиническое наблюдение, в котором, при достаточной иллюстрации этапов течения и диагностики саркоидоза легких и периферических лимфатических узлов, постановка диагноза была затруднена.Поздняя диагностика и отсутствие корректной терапии делает прогноз у больных саркоидозом легких неблагоприятным.Данные морфологические критерии диагностики саркоидоза легких и лимфотических узлов необходимы для использования в практике врача-патоморфолога с целью верификации клинического диагноза, что позволит определить адекватную тактику обследования, введения, коррекцию терапии и оценке прогноза заболевания с учетом, выявленных клинико-лабораторных данных, результатов инструментальных методов исследования.

Ключесвые слова: гранулматозные заболевания легких - саркоидоз - гранулема. 


\section{Введение}

Морфологическая дифференциальная диагностика саркоидоза с другими гранулематозными диссеминированными заболеваниями легких остается актуальной проблемой фтизиатрии и пульмонологии.

В настоящее время повсеместно наблюдается рост заболеваемости и распространенности саркоидоза, заболевание встречается у людей молодого и среднего возраста [1-3].

Саркоидоз, как известно, системное воспалительное заболевание неизвестной природы, но различия в клинико-морфологических проявлениях саркоидоза заставляет думать о сочетании различных этиологических факторов[5,6]. Заболевание характеризуется образованием гранулём без казеозного некроза, мультисистемным поражением различных органов и активацией Т-клеток в зоне гранулёматозного воспаления с высвобождением различных хемокинов и цитокинов, включая фактор некроза опухоли (TNF-альфа)[4,7].

В клинической практике саркоидоз легких чаще приходится дифференцировать с гранулематозным процессом при туберкулезе легких, реже с другими диссеминированными процессами, таких как гранулематоз $\mathrm{X}$, аллергический альвеолит, лейомиоматоз и тд. Нередко пациенты, не обосновано, получают специфическую терапию в связи с ошибочной морфологической интерпретацией гранулематозного процесса. Не смотря на широкое внедрение современных методов лучевой диагностики, как КТ и МРТ-исследования, порой точная верификация клинического диагноза становиться возможной после морфологической оценки материала торакобиопсий. При этом следует отметить, что здесь большое значение имеет знание гистологических критериев морфологической дифференциальной диагностики туберкулеза и саркоидоза легких

\section{Материал и методы исследования}

Проведен анализ истории болезней и операционнобиопсийного материала легких, исследованные в терапевтическом отделении больницы Медицинского центра Управления делами Президента РК (г. Астана) и в патоморфологической лаборатории Карагандинского Государственного Медицинского Университета (г.Караганда).

Изготовленные морфологической микропрепараты, с целью патоморфологических изменений, просматривали на специализированном аппаратном компьютеризированном комплексе фирмы «Leicamicrosystems» (Швеция) на микроскопе «LeicaDM 1000», который предназначен для изучения гистологических микропрепаратов с последующим цифровым цветным фотографированием при увеличении 100,200 и 400.

\section{Описание случая}

Приводим пример из практики, когда имела место ошибочная диагностика выявленных гранулематозных образований в лёгких, которые были оценены как опухолевый процесс.

Пациентка А., 1959 г.р., обратилась в терапевтическое отделение поликлиники при Больнице Управления делами президента РК с жалобами на одышку при небольшой физической нагрузке, кашель с мокротой желтого цвета, эпизодические боли в левой половине грудной клетки.

Из ананеза известно, чтосчитает себя больной с 2014года,самостоятельно принимала препараты от кашля, отмечала потерю веса тела - не знает на сколько. Со слов пациентки, обследовалась в Корее, где по результатам КТ, ПЭТ(позитронно-эмиссионная томография с использование радиофармпрепарата фтордиоксиглюкозы) и биопсии легких был выстален диагноз «cancer», что было подтверждено представленной медицинской документации. Потом обратилась самостоятельно и была исследована кровь в Германии (?), где с ее слов был подтверждён рак легких, но подтверждающие документы обследования не были предоставлены.

Объективно: общее состояние средней тяжести за счет астенического и бронхитического синдромов, носовое дыхание не нарушено, в легких на фоне ослабленного дыхания сухие хрипы. ЧД - 18/мин., SaO98\%, PS-88/ min, АД 180-120м.рт.ст., тоны сердца приглушены, ритм правильный, ЧСС-88/мин.

Лабораторно-инструментальные исследования:

Из выписки, представленой из медицинского учреждения в Корее, следует: биохимический анализ крови от 08.11.2014г., - лабораторные данные в пределах нормы. Данные КТ и МРТ от 17.10.2014г.- предыдущее состояние левой лобэктомии вместе с легким плевральным утолщением вдоль левой задней плевры. Изменения нескольких узлов разного калибра в виде некротических масс подобных очагам влевой нижней доле легкого. Небольшой лимфоузел в средостении. Заключение: больше данных за онкопроцесс (образования, лимфаденопатия). Рекомендована клиновидная биопсия, для исключения первичного диагноза - рака легких.По данным ПЭТ от 11.04.2014г., отмечались множественные гипертрофированные узлы в билатеральной, цервикальной, подвздошной и паховой областях. Очаговое уплотнение в нижней доле легкого. На основании чего был выставлен диагноз: Хронический бронхит в стадии неполной ремиссии. ДН-2. C-r легких?

В последующем по данным ПЭТ от 21.08.2015г., отмечены новообразованные гипертрофические очаги в обоих легких, несколько мелких гипертрофических очагов рассредоточеных в двух легочных полях. Заключение: необходима дифференциальная диагностика активного воспалительного и злокачественного поражения легких.

В торакальном отделении хирургии г.Сеула произвели резекцию левой верхней доли легкого и удаление лимфатического узла. Было принято решение провести последующее врачебное наблюдение, включая лучевое исследование.

Макроскопическое описание от 25.07.2014г.: материал, ткань легкого, размером 20x9х4cм, весом 177,3гр., узел левой верхней доли, $2.5 \times 0,5 \times 05 \mathrm{~cm}, 0.6 \mathrm{cm.Заключение:}$ Хроническое пролиферативное воспаление.

Гистологическое исследование операционного материала:ткани легкого - распространенное хроническое пролиферативное воспаление с центральной гиалинизацией и двояко преломляющим кристаллом (кальцификацией). Не некротизирующий пролиферативный артериит; ткани л/ узлов (прикорневые, трахеобронхиальные, парааортальные и перибронхиальные) дается заключение: распространенное хроническое пролиферативное воспаление с центральной гиалинизацией. AFB (A1,2,3,4,7), GMS (A4), PAS (A1,4): отрицательно для микроорганизмов. МБТ ПЦР В режиме реального времени $(\mathrm{A} 1,4)$ отрицательно. 

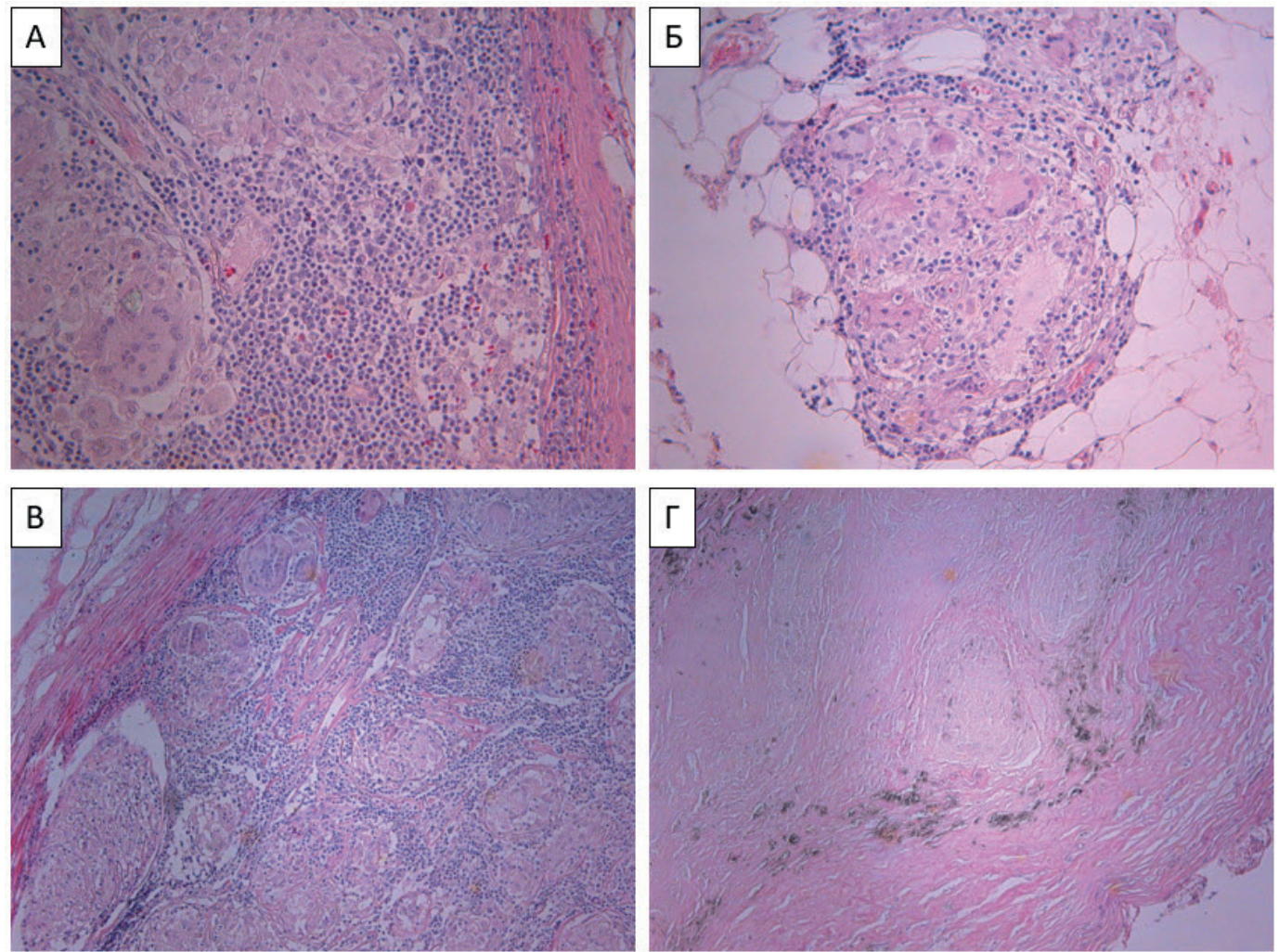

Рисунок 1 - Гигантоклеточные гранулемы в ткани лимфатического узла при саркоидозе: а - фиброз капсула и гигантоклеточные гранулемы (б), в - гранулемы, вокруг концентрически расположенные волокна грубоволокнистой ткани с лимфоидной инфильтрацией; г - фиброз и «тельца Хамазаки-Весеберга». Окраска: гематоксилином и эозином. Ув.: х 200.
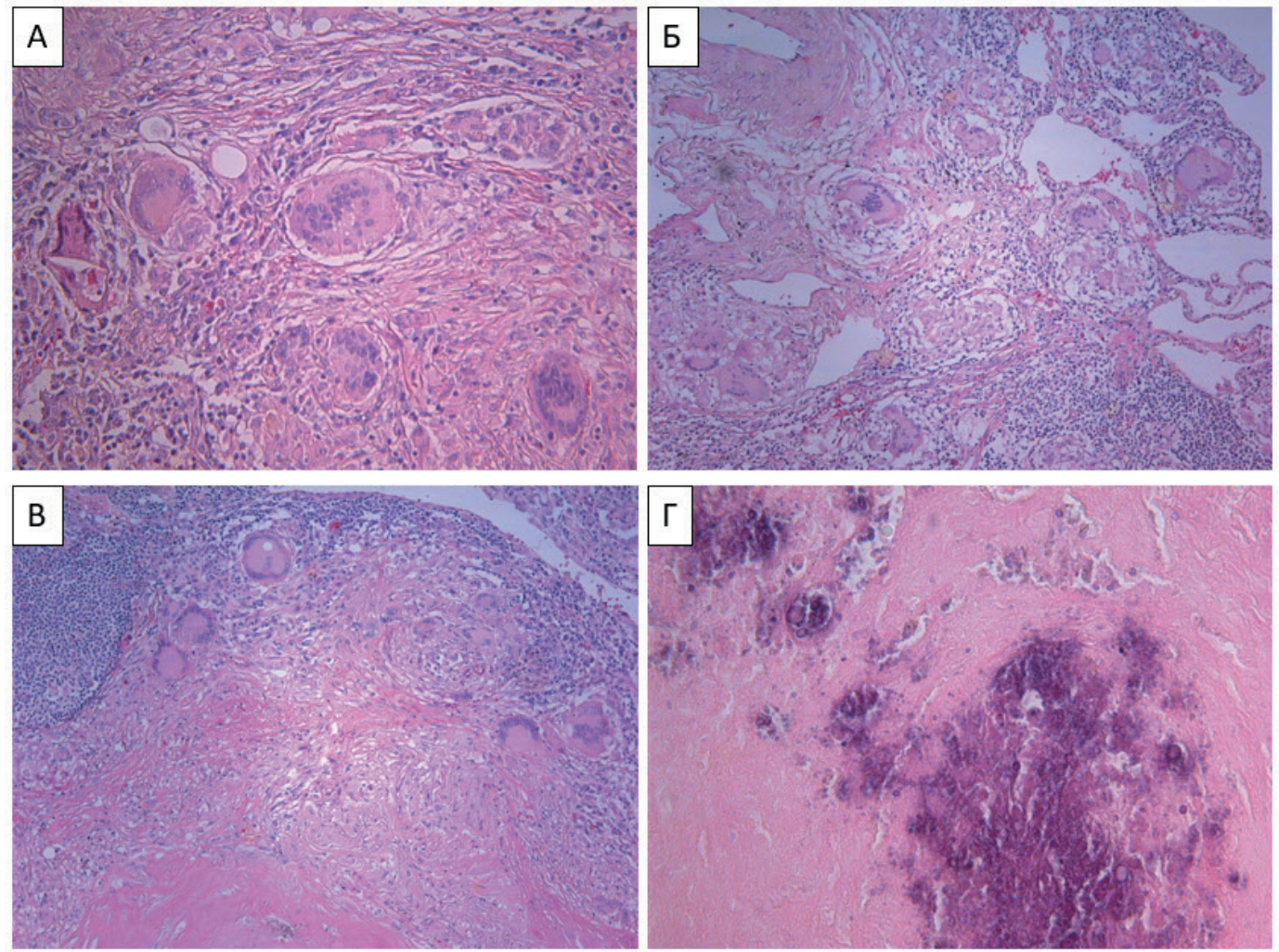

Рисунок 2 - Гранулемы при саркоидозе в легких: а, б - гигантоклеточные гранулемы с клетками ПироговаЛангханса; в - гигантоклеточная гранулема с фиброз и явлением гиалиноза; г - тельца Шауманна. Окраска: гематоксилином и эозином. Ув.: х 200. 
Лечение получала симптоматическое. Так как состояние больной ухудшилось, а лечение не дало положительного эффекта, гистологический материал был направлен на консультацию на кафедру патологической анатомии Карагандинского государственного медицинского университета, куда были представлены микропрепараты ткани легкого и лимфатического узла по данному наблюдению с целью морфологической верификации клинического диагноза.

Результат гистологического исследования данных микропрепаратов показали, что представлена ткань лимфатического узла с фиброзированной капсулой, где выявляются множественные гранулематозными образованиями в составе которых обнаруживаются скопления лимфоидных, макрофагальных и многоядерных гигантских клеток типа Пирогова-Лангханса(рис.1 а,б). Гранулематозные структуры отграничиваются между собой прослойками грубоволокнистой соединительной ткани с полями фиброза и гиалиноза, где имеется значительное число пигментированных клеток «телец ХамазакиВесеберга», в фиброзированной капсуле лимфатического узла наблюдается скопление лимфоидных клеток (рис.1 в,г).

Заключение: Гигантоклеточные гранулемы в ткани лимфатического узла при саркоидозе (Саркоидозная гранулематозная лимфоаденопатия).

При микроскопическом исследовании ткани легкого были выявлены множественные гранулематозные образования различных по диаметру, местами располагающиеся близко друг к другу, образуя гранулематозный конгломерат, разделенные между собой оплетающими волокнами грубоволокнистой соединительной ткании четко очерченных гранулематозных структур(рис.2в). Гранулемы представлены гигантскими и многоядерными клетками(рис.2a, б), окруженные значительным числом лимфоцитов, гранулематозные образования располагаются периваскулярно. Кроме того в различных участках фиброзирования выявляются множественные очаги петрификации, в виде астероидных телец Шауманна и значительное число пигментированных клеток «телец Хамазаки-Весеберга» (рис.1г, 2г).

Заключение: Саркоидозные гигантоклеточные гранулемы, 3-4 стадии с явлением фиброза и гиалиноза.

\section{Обсуждение}

Приведенный клинический случай очередной раз показывает сложность морфологического обоснования саркоидоза легкого и необходимости учета всех дифференциальных признаков гранулематозных процессов, без знания которых возможна ошибочная трактовки патоморфологических изменений.Поздняя диагностикаприводит к не корректной терапии делает прогноз у больных саркоидозом легких неблагоприятным.

\section{Выводы}

Данные морфологические критерии диагностики саркоидоза (периваскулярно располагающиеся не казеинфицирующие гигантоклеточные гранулемы c концентрически расположенными волокнами грубоволокнистой ткани с лимфоидной инфильтрацией, с наличием телец Хамазаки-Весеберга, Шауманна), что необходимо знать в практике врача-патоморфолога с целью верификации клинического диагноза, что позволит определить своевременно адекватную тактику обследования и коррекцию терапии, дать оценку прогноза заболевания с учетом, выявленных клинико-лабораторных данных, результатов инструментальных методов исследования.

\section{References}

1. Muhina N.A. Intersticial'nyeboleznilegkih: Prakticheskoerukovodstvo. Pod red. N.A. Muhina. M.: Littera, $2007 ; 432$ s.

2. Chuchalina L.G. Klinicheskierekomendacii v pul'monologii/pod red. L.G. Chuchalina. M.: GJeOTLR-Media, $2009 ; 312$ s.

3. Chuchalin A.G. Sarkoidoz: Monografija, pod red. A.A. Vizelja. M.: Izdatel'skij holding «Atmosfera», $2010 ; 416$ s.

4. Babanov S.A. Problemy differencial'noj diagnostiki sarkoidoza. S.A. Babanov. Novosti mediciny i farmacii. 2013. № 1 (454); S.7-11.

5. Borisov S.E. Morfologicheskaja harakteristika sarkoidoza i osobennosti ego diagnostiki pri razlichnyh lokalizacijah processa. S.E. Borisov, I.P. Solov'eva, E.L. Goncharova. Sarkoidoz: otgipotezy k praktike. Podred. A.A. Vizelja. Kazan', 2004; S. 56-64

6. Vizel’ I.Ju. Sarkoidoz: vzgljadnarealii segodnja shnegodnja. Consiliummedicum. 2012. T. 14; № 3. S. 86-88.

7. Chuchalin A.G. idr. Diagnostika i lechenie sarkoidoza. Rezjumefederal'nyh klinicheskih rekomendacij. Chast' II. Diagnostika, lechenie, prognoz. Vestnik sovremennoj klin. mediciny; 2014; T. 7, № 5. S. 73-81.

How to cite this article: Maida Tussupbekova, Rosa Bakenova, Leila Stabayeva, Rayhan Nygizbaeva, Gulnazira Imanbayeva. Features of the clinical and morphological picture of pulmonary sarcoidosis: a description of the clinical case [In Russian]. J Clin Med Kaz 2017;4(46):33-36 